\title{
\begin{tabular}{|c|}
\hline Public \\
health series \\
no 5 \\
Series editor \\
Graham Nielsen \\
\hline
\end{tabular}
}

\section{Health education and promotion for STD prevention: lessons for the next millennium}

\author{
William W Darrow
}

Objective: To review the evolution of health promotion for STD prevention.

Main observations: Information and education programmes were provided at the beginning of $\frac{\overrightarrow{0}}{\text { ? }}$ the 20th century to warn the public about the dangers of venereal infection and to support the $\vec{\Rightarrow}$ medical model of case identification and case management under the care of qualified physi- $\frac{0}{0}$ cians. The public health approach offered advice about chemical, chemotherapeutic, and barrier $\frac{0}{5}$ prophylaxis, but avoided the issue of social prophylaxis. With the failure of antimicrobial agents $\overline{\bar{\sigma}}$ to eradicate syphilis in the 1960s, rapid increases of viral sexually transmitted diseases (STDs) and $\bar{D}$ resistant strains of gonorrhoea in the 1970s, and the discovery of AIDS in the 1980s, alternatives 0 to the traditional public health approach were sought and supported with a modest increase of resources. Three major innovations have been introduced to STD prevention as a result: social ${ }_{-}^{\circ}$ marketing, community involvement, and behaviour change programmes based on social and $\vec{\omega}$ psychological concepts and theoretical models.

Conclusions: Health promotion for STD prevention in the future will be characterised by care- $\stackrel{5}{=}$ ful assessments of the social and behavioural determinants of sexual risk taking, development and implementation of targeted interventions designed to reduce risk taking, and evaluation of ${ }_{\infty}^{\text {N }}$ social and behavioural interventions for improvements in STD prevention.

(Genitourin Med 1997;73:88-94)

Keywords: AIDS education; behaviour change; health promotion; STD prevention

\section{Introduction}

Health education refers to the process of providing accurate information about the course of biomedical conditions, risk factors, people at increased risk, prudent preventive actions, available services and therapies, and possible outcomes of untreated conditions (complications and sequelae). ${ }^{1}$ Health promotion refers to a comprehensive, practical, and flexible approach to changing behaviours associated with disease acquisition and transmission. ${ }^{2}$ Health promotion includes health education and much more. ${ }^{3}$ It requires a major commitment of resources to: (1) define and assess a health problem; (2) plan a systematic approach to understanding and addressing the determinants of a problem; (3) develop and test viable interventions; (4) implement appropriate programmes and activities for various target populations; (5) evaluate effectiveness, benefits, and costs; and (6) revise programme strategies based on research and evaluation data to improve outcomes for susceptible populations. ${ }^{4}$

Programmes for the prevention and control of syphilis, gonorrhoea, and other sexually transmitted diseases (STDs) have included a health education component since they were first devised early in the 20th century, ${ }^{5}$ but it has only been in the past decade that public health officials have recognised a need for health promotion. This report reviews health education to promote social, chemical, chemotherapeutic, and barrier prophylaxis, and recent attempts to influence behaviours through social marketing, community level interventions, and theoretically guided intra- personal and interpersonal approaches to health promotion.

\section{Venereal disease control}

Basic biomedical breakthroughs at the beginning of the 20th century led to the establish-o ment of venereal disease (VD) control on programmes during the first world war. ${ }^{6}$ In 1905, Schaudinn and Hoffmann identified the spirochete, Treponema pallidum, that causes $\delta$ syphilis. In 1906, August von Wassermann and colleagues developed a complement fixa- 9 tion assay to test blood for antibody to $T$ D pallidum. In 1907, Paul Ehrlich began to experiment with therapies for syphilis, and in $\mathcal{O}$ 1910 announced that he had found the "magic N bullet," Salvarsan 606 . With the onset of the N first world war, military services in Europe and $\frac{\omega}{2}$ North America began to screen volunteers for 0 antibody to $T$ pallidum and found the prevalence to be significant. For example, about $6 \% \stackrel{?}{\rightarrow}$ of men tested in the United States had a posi- $\frac{T}{0}$ tive reaction to the Wassermann test. ${ }^{7}$ In $\frac{0}{\mathbb{D}}$ response to this finding, public health officials $\frac{?}{\mathbb{D}}$ drew up plans to combat syphilis and other STDs. The 11 point programme developed in the United States in 1917 included health education activities for soldiers, their sex partners, and the general public. ${ }^{8}$

To educate military recruits about the dangers of venereal infection, the US War Department showed a motion picture, "Fit to Fight," during basic training. The film was evaluated by J B Watson and Karl Lashley of Johns Hopkins University in 1919.9 Results indicated that $28 \%$ of those who saw the 
movie retained facts about VD for up to 6 months, but the movie had very little influence on motivations to engage in extramarital sex or on sex behaviours. Venereal infections and visits to prophylactic stations increased among the 6400 servicemen who saw the film. Although this study provided no evidence for the value of showing a melodramatic movie about VD to military personnel, the practice of producing movies about the horrors of VD and showing them to young people continued for decades. Only the practice of critically evaluating educational interventions and reporting results to the public ceased. ${ }^{10}$

Throughout the greater portion of the 20 th century, health education served to support the medical model of VD control (fig 1). Major objectives of VD education were to discourage extramarital sexual activities and to provide information about the signs of venereal infection so people would seek proper medical care. ${ }^{11}$ Public health officials were hesitant to provide information about chemical, chemotherapeutic, and barrier prophylaxis to young adults because it was believed that such information would provoke immoral sexual liaisons. ${ }^{12}$ Social prophylaxis was to be taught by religious leaders and parents, not by health professionals.

\section{AIDS exceptionalism}

Many innovations in VD education were explored before acquired immune deficiency syndrome (AIDS) was described in 1981, but most of these efforts failed to secure adequate support. For example, a "behavioral research activity unit" was established at the US Communicable Disease Center (CDC) in 1962 to conduct studies of sexual behaviours among youth" ${ }^{13}$ and "community mobilization for eradication" (CME) was initiated to support efforts to eliminate syphilis as a public health problem in the $1960 \mathrm{~s},{ }^{14}$ but these attempts to use social and behavioural science and community based activism to complement biomedical interventions never gained wide or sustained support. Traditional methods of VD

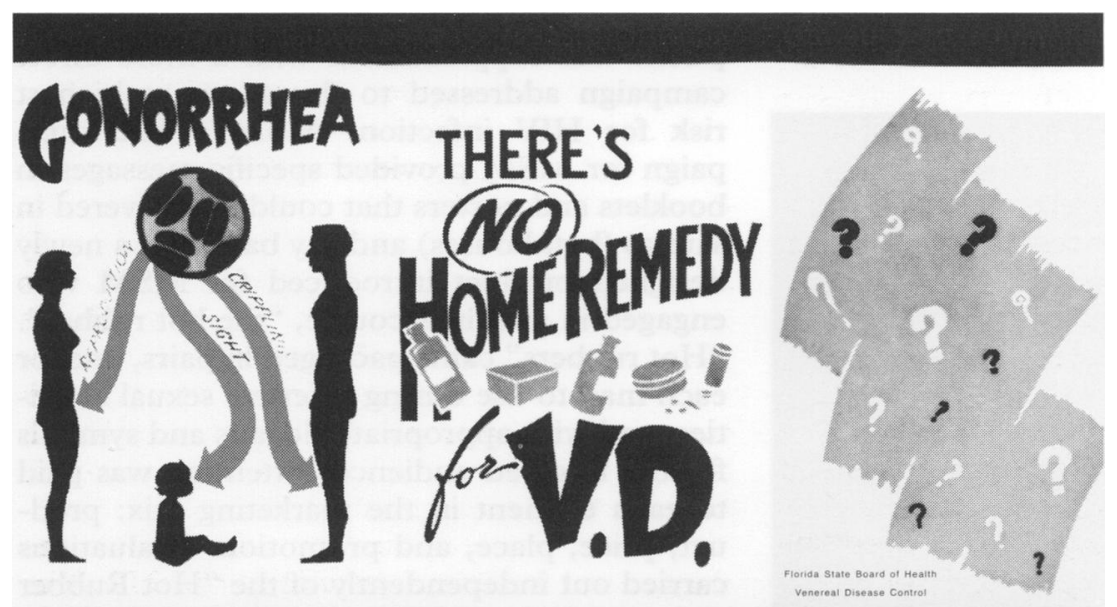

Figure 1 VD education in the 1960s emphasised signs and sequelae to encourage people to seek proper medical care, as illustrated in this pamphlet from the Florida State Board of Health (1961). case finding and control (screening, premarital and perinatal testing, contact tracing, and clinic based case management) prevailed until the mid 1980s when nations began to confront the AIDS crisis. ${ }^{15}$

Initially, public health authorities responded to AIDS by conducting surveillance and epidemiological research to determine prevalence, help identify the aetiological agent, and assess risk factors and modes of transmission. ${ }^{16}$ National programmes were launched in the mid 1980s to educate the public and dispel myths about casual transmission. ${ }^{17}$ Mass media campaigns succeeded in increasing awareness, concern, and knowledge. ${ }^{18}$ Targeted interventions were directed at people who engaged in behaviours that might put them at risk of infection with human immunodeficiency virus (HIV) or might involve them in HIV transmission. Interventions included modifications of the traditional measures used to prevent and control VD; confidential counselling, partner notification, and case management. ${ }^{19}$ Evaluations of counselling and testing, referral for case management, and partner notification (CTRPN) indicated that these interventions were insufficient to produce lasting changes in behaviour. ${ }^{20}$ More comprehensive efforts would be required to stop transmission of HIV.

Alternative approaches to HIV prevention include social marketing (as opposed to mass media information campaigns), community level (as opposed to clinic based) interventions, and carefully planned activities (grounded in social science and behavioural theories) that are designed to change behaviours. For example, the "Stop AIDS" project introduced in San Francisco in the early 1980s was created to involve members of the "gay community" in the planning, implementation, and evaluation of a package of mutually reinforcing risk reduction activities. ${ }^{21}$ Peers educated peers through telephone hotlines, safer sex parties, and ongoing support groups. Through collective action, social norms supporting "safer sex" with fewer partners were established. Evidence suggested that these innovative strategies provided a greater impact on behaviour change among men who have sex with men (MSM) than traditional public health methods of VD control. ${ }^{22}$

\section{STD prevention in the 1990 s}

Strategies for STD prevention in the 1990s are characterised by the identification of behaviours involved in STD transmission, analysis of the determinants of those behaviours in various social groups, and the development, testing, and evaluation of social and behavioural interventions to induce and maintain behaviour change. The goal of STD prevention programmes is not to change the behaviour of everyone, but to modify the behaviours of those most likely to contract and spread STDs. ${ }^{23}$ Tools for accomplishing behavioural objectives include social marketing, community as well as individual level interventions, and theoretically guided approaches to behaviour change. 

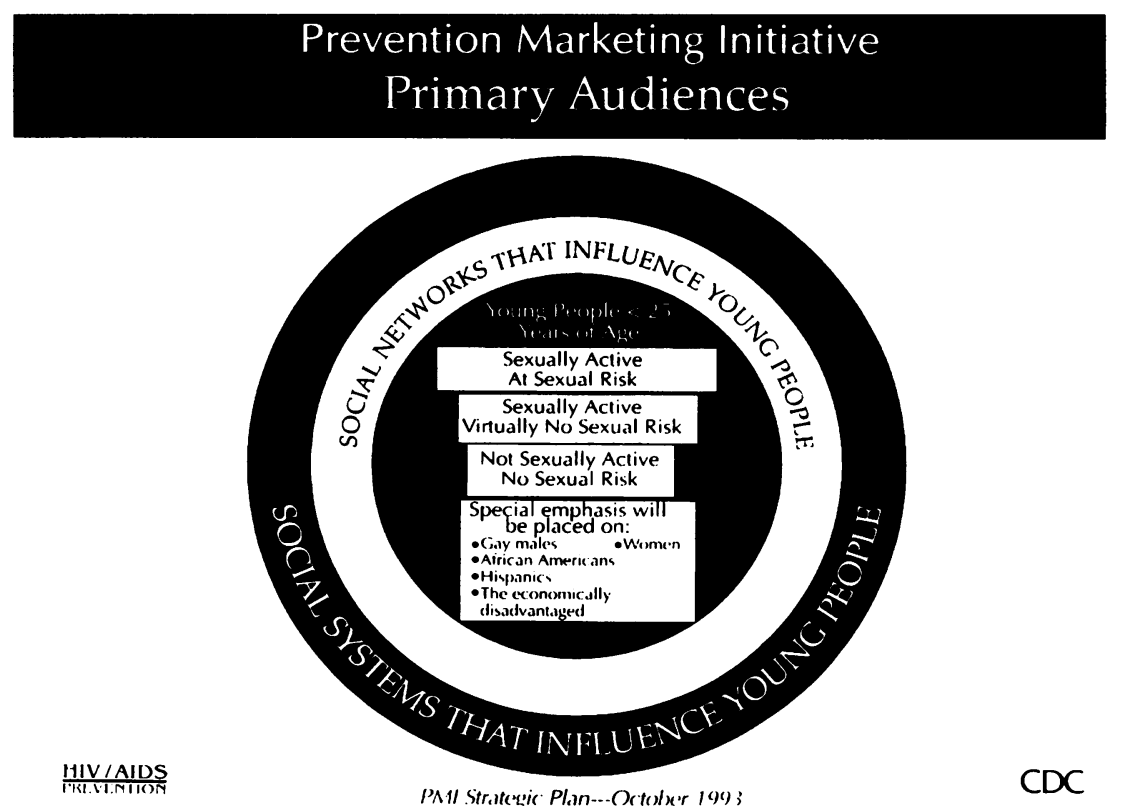

CDC

Figure 2 Prevention marketing for HIVIAIDS identified and analysed target audiences, as illustrated in this chart from the Centers for Disease Control and Prevention (CDC) Prevention Marketing Initiative (PMI) Strategic Plan (October 1993).

SOCIAL MARKETING

A comprehensive, integrated, and yet flexible approach to STD prevention puts the consumers (and potential consumers) of STD preventive services at the centre of attention. ${ }^{24}$ Data are gathered about those infected and those most likely to become infected to determine their attitudes, motivations, beliefs, values, skills, intentions, and behaviours. Their participation in prevention programmes is sought at the outset to understand the context and conditions for risk taking, to estimate the potential impact of conceivable interventions, and to develop appropriate messages, select appropriate media, choose appropriate role models, and test various strategies before programmes are formulated for widescale implementation. ${ }^{25}$

Product, place, price, and promotion are the four major variables to consider when advocating a social idea (such as sexual health), a prophylactic (such as a latex condom), or a health behaviour (such as the proper and consistent use of a latex condom to enhance sexual health and prevent STDs). ${ }^{26}$

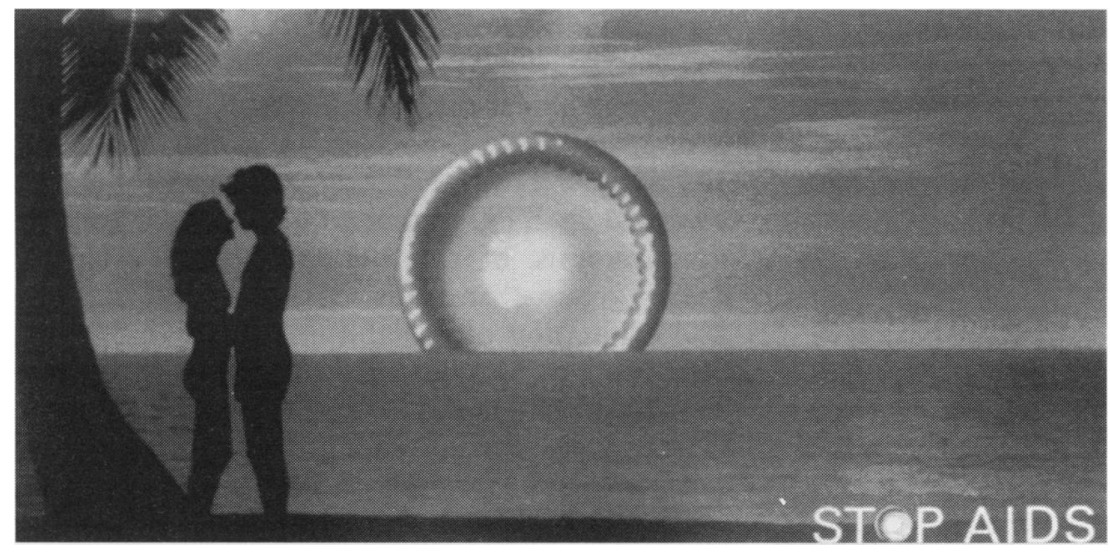

Figure 3 The Swiss "Stop AIDS" project" repeatedly displayed a condom in place of a moon from 1987 to 1992 to remind young sexually active people that they should protect themselves and others from HIV infection, at home and while abroad, as illustrated in this poster (1988). (Reproduced with permission of the Swiss "Stop AIDS" campaign.)
To be successful, a comprehensive plan must be established and specific strategies must be tested that combine the four major variables in an appropriate "marketing mix" (fig 2). The product must be appealing to consumers (and potential consumers); it must be placed in a position where it is frequently noticed and easily accessible; perceived rewards for use musto exceed costs (psychological as well as finan cial); and the image portrayed must excite the interest of users and potential users. ${ }^{27}$

The social marketing framework contains another critical concept that must be carefully? considered in health promotion: audience seg $=$ mentation. ${ }^{28}$ Efforts to prevent the spread ofo HIV and other STDs must be diverse becauseo some people are concerned about the risks of? casual transmission, others are concerned $\mathbb{Q}$ about transmission from contaminated needles or syringes, and still others are con- cerned about sexual transmission. Problemsarise when a message carefully crafted for one $\vec{\omega}$ segment of society is shown to the wronges group. For example, public funding for $\mathrm{HIV}_{-}^{-}$ prevention programmes in the United States was seriously threatened by conservative lawmakers in the late $1980 \mathrm{~s}$ who discovered that ao homosexual service organisation in New York City had used "taxpayers' money" to produce "hot and horny" (but safe) videotapes and? other explicit materials to "eroticise safer sex"
for MSM.

The Swiss "hot rubber" campaign of the mid 1980s provides a good example of hows the principles of social marketing have been? applied to HIV prevention. ${ }^{30}$ Epidemiologistsa in the Swiss Federal Health Office realisedo when they began recording cases of AIDS that Switzerland had the highest rate of AIDS in Europe and encouraged legislators, community representatives, and others to work together creatively to address this problem. A mass media campaign was developed to edu-i cate the general public (in four languages). about AIDS. The educational campaigno showed a pink condom instead of the moon shining brightly over the skyline of one of Switzerland's largest cities (or a vacation destination (fig 3)) and a "Stop AIDS" slogan. ${ }^{31}$

The educational campaign for the genera public was supplemented with a more directin campaign addressed to the group at highestu risk for HIV infection-MSM.32 The cam paign for MSM provided specific messages in booklets and posters that could be delivered in saunas (bathhouses) and gay bars, and a newly. designed product introduced for MSM who 0 engaged in anal intercourse, "the hot rubber" "Hot rubbers" came packaged in pairs, one for? each man to use during insertive sexual activi ties, and with appropriate slogans and symbols? for the targeted audience. Attention was paid to each element in the marketing mix: prods uct, price, place, and promotion. Evaluations carried out independently of the "Hot Rubber Company" showed that about four out of five MSM in Switzerland reported having used condoms within two years of the initiation of the campaign. ${ }^{33}$

Mass media campaigns carried out in other 
countries during the mid to late 1980 s have not been able to demonstrate the same measure of success observed in Switzerland. "America responds to AIDS," 34 "Don't die of ignorance," 35 and "the grim reaper" 36 were national campaigns conducted in the United States, the United Kingdom, and Australia, respectively, to inform the general public about the threat of AIDS and heterosexual transmission of HIV in particular. Goals were to provide accurate information about AIDS and dispel myths, build support for HIV prevention programmes and create empathy for those infected with $\mathrm{HIV}$, and encourage concerned individuals to seek additional information specific to their situations, be tested for HIV antibody (if warranted by histories of possible exposure), and enter into early intervention programmes if infected.

Evaluations of these national AIDS information campaigns showed that they succeeded in increasing awareness of AIDS and raising concerns about transmission, but additional problems arose as a result of these well intentioned efforts. ${ }^{37}$ Images of a scythe carrying skeleton who bowled over helpless humans like wooden pins in an underworld bowling alley created unnecessary fears and anxieties among the worried well, sent many low risk people into clinics for counselling and HIV antibody testing, and increased stigmatisation of minorities and discrimination against those suspected or known to be infected with HIV. ${ }^{36}$ As a consequence of these adverse reactions to public service announcements and related materials, national programmes began to alter their approaches to health education for STD prevention by integrating - as the Swiss had done-national information campaigns with local efforts to carry out effective interventions in diverse communities. ${ }^{38}$

Social marketing principles and practices have steered HIV prevention efforts in the developing countries of Africa, Asia, the Caribbean, and Latin America. ${ }^{39} \mathrm{~A}$ recent example comes from Tanzania where a "fleet of hope" campaign was developed to use symbols, group dynamics, and institutional collaboration among non-governmental and religious organisations to offer young people three options: abstinence, fidelity, and condom use. ${ }^{40}$ The idea was to approach the problem of AIDS prevention indirectly through images of a population threatened by a rising tide of HIV infection. Escape from danger was offered by climbing aboard a boat containing other people who had chosen one of the three available options. Effectiveness of a resource package designed to support the campaign was evaluated through surveys and focus groups. Feedback from potential consumers indicated that "the three boats were full of holes." Additions and adjustments to the campaign had to be made before full scale implementation. By conducting market research, pretesting and revising materials, developing implementation plans and plans for continuous evaluation, the Tanzania AIDS project has managed to avoid many of the pitfalls that have befallen so many educational campaigns conducted elsewhere.
COMMUNITY INVOLVEMENT

Communities might be the best unit of analysis for STD prevention programmes because communities are composed of individuals, couples, families, and social networks through which infectious agents might be transmitted. ${ }^{41}$ Communities can be identified by spatial boundaries as neighbourhoods, villages, or inner city areas often are. They also can be identified by ascribed or achieved characteristics such as "African American," "gay," or "persons living with HIV/AIDS." One of the most important trends in health promotion is the inclusion of communities most affected by the HIV epidemic and community representatives in the planning, conduct, and evaluation of STD prevention activities.

Efforts to intervene in and with communities are potentially more powerful in bringing about change than traditional educational strategies that send messages out through mass communication channels or distribute them one at a time as is done over telephone hotlines or in confidential counselling sessions. ${ }^{42}$ Social norms govern human behaviour and communities establish, maintain, and enforce the rules for interpersonal conduct. When communities mobilise to understand, address, and solve a problem, they can be highly effective, as has been witnessed in the San Francisco "Stop AIDS" project and the Swiss "hot rubber" campaign.

Communities were the unit of analysis in the "AIDS Community Demonstration Projects" (ACDP) sponsored by the US CDC and carried out by five municipal health departments, social and behavioural scientists, community representatives, and peer educators. ${ }^{43}$ Ten communities were chosen to provide interventions consisting of "small media" materials (brochures, pamphlets, flyers, and newsletters) which contained carefully composed role model stories of people living in the area. The materials were distributed by members of the community, who also distributed condoms and bleach to injecting drug users and were available to answer questions. Communities with demographic and other characteristics similar to intervention sites received no interventions and served as control sites.

From February 1991 to the end of December 1993, cross sectional data were collected in 10 waves from people randomly encountered on the streets of the 16 communities participating in ACDP to measure behaviour patterns, exposure to materials, and "stages of change". Results now being reported from these community studies show significant increases in consistent condom use during vaginal intercourse with occasional partners and consistent bleach use among injecting drug users in intervention sites. ${ }^{44}$ Furthermore, positive effects on these behaviours are linked with reported exposures to prevention materials.

Principles of community intervention have been applied to other populations in other settings. Several studies of HIV prevention among MSM in North America have demonstrated reductions in risky sex behaviour as a result of 
the influence of peers ${ }^{45}$ and opinion leaders ${ }^{46}$ in homosexual communities. Studies of commercial sex workers, brothel owners and operators, and others involved in sex work in Ghana, ${ }^{47}$ India, ${ }^{48}$ Kenya, $^{49}$ Thailand, $^{50}$ and Zimbabwe ${ }^{51}$ have shown the benefits of peer education in promoting condom use to prevent HIV and other STDs. In the Caribbean, entire villages have been educated by travelling theatre troupes who involve villagers in their presentations and plays about the effects of HIV disease. ${ }^{52}$ Communities have even been used successfully as the unit of analysis in research focusing on STD prevention..$^{53}$

Community level interventions have evolved in the field of STD prevention from early attempts to describe patterns of STD infection and transmission in the $1930 \mathrm{~s},{ }^{54} 1950 \mathrm{~s},{ }^{55}$ and 1970 s. ${ }^{56}$ However, the resources necessary to plan and conduct experimental or quasiexperimental intervention trials of the impact of these interventions were unavailable before the threat of AIDS. ${ }^{57}$ Furthermore, early investigations did not benefit from the evolution of social and behavioural theories about health, prophylactic and sexual behaviours, and theories about how to change behaviours that lead to HIV infection and the spread of STDs.

\section{BEHAVIOUR CHANGE}

There was a time when most people believed that sexual behaviour was driven by "raging hormones" and biological forces that could not be altered by social or behavioural interventions. Unfortunately, many influential people involved in VD control thought that "social prophylaxis" was not the business of public health. As a consequence, narrowly defined medical solutions to syphilis and other VD problems were sought. The medical model of massive screening and selective testing to identify cases, treatment with antimicrobial agents and case management under the care of qualified clinicians, and case finding through contact tracing prevailed as the dominant public health strategy for VD control in many places throughout the 20th century. ${ }^{58}$

In spite of intensive efforts, medical solutions for the problem of syphilis failed in the 1960s. Gonorrhoea, chlamydia, and other STDs caused by viruses (such as genital herpes, genital warts, and hepatitis B) emerged as major public health problems in the 1970 s. Yet when AIDS was discovered in the 1980 s, traditional methods of controlling bacterial STDs were proposed as the solution: screening, testing, counselling in clinical settings, referral for case management, and partner notification. No treatment or vaccine was readily available, medical approaches soon appeared to be insufficient to stop the spread of the AIDS virus, and programmes for behaviour change began to gather tepid support. ${ }^{59}$

As it became increasingly apparent that "medical miracles" would not solve the AIDS pandemic, more solid support for health promotion produced more effective and more extensive programmes for behaviour change. For example, the ACDP benefited greatly from the collaboration of local health officials, com- munity representatives, and social and behavioural scientists who had been working on related problems in promoting health and preventing disease. These social and behavioural scientists brought with them the theoretical models they had been developing, testing, and refining (through induction and deduction) to address the problem of AIDS. Theoretical models such as the health belief model, ${ }^{60}$ the theory of reasoned action, ${ }^{61}$ social cognition theory, ${ }^{62}$ and the transtheoretical model ("stages of change") ${ }^{63}$ were applied to the prob-? lem of STD prevention on a scale that was $\vec{\Rightarrow}$ unimaginable before the AIDS pandemic. Although earlier efforts to understand sexual risk taking ${ }^{64}$ and evaluate prevention measures through condom promotion ${ }^{65}$ had tried to use $\frac{\Phi}{\mathscr{Q}}$ social and behavioural theories, these efforts received minimal support.

Theoretically guided strategies for STD pre-. vention and the promotion of sexual health are $\vec{\omega}$ now the rule and not the exception. Evidence for the effectiveness of social and behavioural interventions in changing sexual, prophylactic, drug using, and other behaviours is just begin- $\infty$ ning to be reported, ${ }^{66}$ but it is coming in. ${ }^{67} \circ$ Examples can be offered in many settings, including small group sessions where informa- $\rightarrow$ tion is provided to people at risk, motivation is stimulated, and self protection skills are taught, practised, and learnt. ${ }^{68}$

Project ARIES ${ }^{69}$ was developed in the late 1980s for MSM in Jackson, Mississippi, a city far from the coastal ports and urban AIDS epicentres of New York and San Francisco. The intervention proposed for MSM in this envi- $\stackrel{\odot}{\triangle}$ ronment was a series of 12 workshops where participants would: (1) review the facts about HIV disease, transmission, and prevention alternatives; (2) provide motivation for one another by assessing risks of infection and possible alternatives; (3) practise negotiating condom use and developing skills for using condoms in ways that would effectively prevent transmission and be satisfying to MSM; (4) discuss lifestyle issues and how to deal with "relapse." Two clinical psychologists helped participants through each session and offered guided feedback, but much of the learning was $\%$ accomplished, as suggested by social psycho- $N$ logical theories, by the interpersonal processes $N$ of group dynamics. ${ }^{70}$

Many other examples of risk reduction occurring with various populations could be cited. They include studies of students in the classroom, ${ }^{71}$ runaway youths in shelters, ${ }^{72}$ o minority inner city young men, ${ }^{73}$ young women, ${ }^{74}$ and other populations. ${ }^{75}$ Such studies $\mathbb{\nabla}$ provide direct benefits to the people involved, indirect benefits to others in the community, and benefits to public health through the growth of scientific knowledge and development of evidence based programmes for the prevention of STDs. ${ }^{76}$

\section{Future directions}

Social marketing, community level interventions, and behaviour change programmes guided by theoretical models appropriated from 
the social and behavioural sciences have risen from the ashes of the AIDS epidemic. With these promising approaches to health promotion, international, national, and local organisations have renewed opportunities to prevent and control STDs by addressing the underlying factors that facilitate transmission. Rates of STDs continue to fall in northern Europe where societies prepared for the HIV epidemic and responded wisely. Sustained efforts should eventually prove equally successful elsewhere if resources are committed to the development, implementation, and evaluation of social and behaviour change programmes.

The rapid explosion of electronic communications has brought diverse peoples together in cybersocieties. ${ }^{77}$ The Internet should serve to link global villages even closer together. ${ }^{78}$ Warnings about coming plagues ${ }^{79}$ should spread rapidly through this emerging technology; responses should be mounted more quickly ${ }^{80}$ By sharing information more widely social marketing and other health promotion efforts should become even more effective. ${ }^{81}$

Evaluation must become an integral component of STD programmes. ${ }^{82}$ When a programme is devised objectives must be established and accomplishments measured so health officials, interested parties, and the general public can determine if objectives are being met. When achievements fall short of initial objectives, the reasons for failure must be identified so adjustments can be made in the delivery of services or expectations for outcomes. The ACDP apparently succeeded in reaching populations at risk in five cities of the United States and encouraging them towards positive changes in health behaviours, but they were abandoned when federal funding for these five year demonstration projects ran out. Efforts must be sustained in high risk populations and begun in others if we are to realise progress in achieving social and behavioural change.

Policy makers want to know "what works". Applied research and demonstration projects are beginning to show the benefits of health promotion in reducing the risk of HIV infection and other STDs. Compared with the costs of treatment ${ }^{83}$ and years of potential life lost as a result of AIDS $^{84}$ health promotion is a bargain. ${ }^{85}$ But the money required to support prevention must come from government sponsorship and, unfortunately, often must compete with programmes for medical care. As governments downsize and ask citizens to use their own resources, individuals must act collectively through the community planning process to identify their priorities, generate political and economic support for promising programmes, and monitor the actions of political appointees and elected officials to ensure that necessary STD prevention endures. ${ }^{86}$

\section{Conclusion}

Modern medicine and the field of health education evolved in the 20th century with the emergence of microbiology and rapid expansion of the life sciences. VD control programmes were established during this era and benefited greatly from scientific discoveries of biological pathogens, diagnostic tests, and antimicrobial agents. These programmes were handicapped, however, by prohibitions regarding the scientific study of human sexuality and the use of behavioural interventions to address the social, psychological, and biological determinants of sexual risk taking. When AIDS programmes based on the traditional medical model failed to halt the spread of HIV, innovative programmes began to look at alternatives. Initial evaluations of social marketing, community level interventions, and facility based interventions grounded in theories of behaviour change show promise, but many challenges lie ahead. Ways of generating and allocating resources for the development, implementation, and maintenance of social and behavioural interventions must be found. Post modern medicine and the field of health promotion must continue to evolve in the 21 st century with the rapid expansion and application of the social and behavioural sciences.

Many thanks to Dr Graham Neilsen, Susan Biersteker, John Potterat, and others who commented on earlier drafts; Kesuri Patel who helped locate references and graphic material; and Roel Coutinho, Frits van Griensven, and Anneke van den Hoek who gave me a place to work on this manuscript in summer 1996.

1 Fineberg HV. Education to prevent AIDS: prospects and obstacles. Science 1988;239:592-6.

2 Green LW, Kreuter MW. Health promotion planning: an educational and environmental approach. 2nd ed. Mountain View, CA: Mayfield, 1991

3 Wardrop K. A framework for health promotion ... a framework for AIDS. Can $\mathcal{F}$ Public Health 1993;84(suppl 1): S9-13.

4 Aggleton P, O'Reilly K, Slutkin G, Davies P. Risking everything? Risk behavior, behavior change, and AIDS. Science $1994 ; 265: 341-5$.

5 Brandt AM. AIDS in historical perspective: four lessons from the history of sexually transmitted diseases. $A m \mathcal{F}$ Public Health 1988;78(April):367-71.

6 Brandt AM. No magic bullet: a social history of venereal disease in the United States since 1880. New York: Oxford University Press, 1985.

7 Siler JF. The prevention and control of venereal diseases in the army of the United States of America. Army Medical the army of the United

8 Vonderlehr RA, Heller JR. The control of venereal disease. New York: Reynal and Hitchcock, 1946.

9 Lashley KS, Watson JB. A psychological study of motion pictures in relation to venereal disease campaigns. Social Hygiene 1921;7:181-219.

10 Darrow WW. Behavioral research and AIDS prevention. Science 1988;239:1477.

11 Parran T. Shadow on the land: syphilis. New York: Reynal and Hitchcock, 1937

12 Rosebury T. Microbes and morals: the strange story of venereal disease. New York: Viking, 1971

13 Forer R. Behavioral science activities in a venereal disease program. Public Health Rep 1965;80:1015-20.

14 Darrow WW. Community mobilization for eradication. Atlanta, GA: Emory University, 1969.

15 Bayer R. Public health policy and the AIDS epidemic: an end to AIDS exceptionalism? $N$ Engl f Med 1991;324: $1500-4$.

16 Darrow WW. AIDS: socioepidemiologic responses to an epidemic. In: Ulack R, Skinner WF, eds. $A I D S$ and the social sciences: common threads. Lexington, KY: The University sciences: common threads. Lexing

17 Kroger F. Preventing HIV infection: educating the general public. F Primary Prevention 1991;12:7-17.

18 Moatti JP, Dab W, Loundon H, Quenel P, Beotzer N, Anes $A$, et al. Impact on the general public of media campaigns Against AIDS: a French evaluation. Health Policy 1992;21: 233-47.

19 Gostin LO. Public health strategies for confronting AIDS. FAMA 1989;261:1621-30.

20 Holtgrave DO, Quails NI, Curran JW, Valdiserri RO, Guinan ME, Parra WC. An overview of the effectiveness Guinan ME, Parra WC. An overview of the effectiveness
and efficiency of HIV prevention programs. Public Health and efficiency of HIV

21 Puckett SB, Bye LL. The stop aids project: an interpersonal AIDS prevention program. San Francisco: The Stop AIDS Project, 1987 .

22 Doll LS, Bye LL. AIDS: where reason prevails .... World Health Forum 1987;8:484-8.

23 Cates W Jr, Hinman AR. AIDS and absolutism-the demand for perfection in prevention. $N$ Engl $\mathcal{F}$ Med 1992; 327:492-4.

24 Smith WA. Organizing large-scale interventions for sexually 
transmitted disease prevention. In: Wasserheit $\mathrm{N}$, Aral SO, Holmes KK, eds. Research issues in human behavio and sexually transmitted diseases in the AIDS era. Washington DC: American Society for Microbiology, 1991:219-42.

25 Kotler P, Roberto EL. Social marketing. New York: Free Press, 1989.

26 Ling JC, Franklin BA, Lindsteadt JF, Gearon SA. Social marketing: its place in public health. Annu Rev Public Health 1992;13:341-62.

27 Lefebvre RC, Flora JA. Social marketing and public health intervention. Health Educ $Q$ 1988;15:299-315.

28 Slater MD, Flora JA. Health lifestyles: audience segmentation analysis for public health intervention. Health Educ 1991;18:221-33.

29 Burkett E. The gravest show on earth: America in the age of AIDS. New York: Houghton Mifflin, 1995.

30 Staub R. The Swiss hot rubber campaign. AIDS Health Promotion Exchange 1988;2:6-7.

31 Kocher KW. The STOP AIDS story, 1987-1992. Bern, Switzerland: STOP AIDS Campaign of the Swiss Aids Foundation and the Federal Office for Public Health, 1993.

32 Staub R. The Swiss hot rubber campaign: self-proclaimed gays take responsibility for informing their community. gays take responsibility for informing their community. In: AIDS prevention through health promotion: facing sensitive

33 Lehmann P, Hausser D, Somaini B, Gutzwiller F. Campaign against AIDS in Switzerland: evaluation of a nation wide educational programme. BMF 1987;295:1118-20.

34 Mason JO, Noble GR, Lindsey BK, Kolbe LJ, Van Ness P, Bowen GS, et al. Current CDC efforts to prevent and control human immunodeficiency virus infection and AIDS in the United States through information and education. Public Health Rep 1988;103:255-60.

35 Mills S, Campbell MJ, Waters WE. Public knowledge of AIDS and the DHSS advertisement campaign. $B M \mathscr{F}$ 1986:293:1089-90.

36 Winn $M$. The grim reaper: Australia's first mass media AIDS education campaign. In: AIDS prevention through health promotion: facing sensitive issues. Geneva: World Health Organisation, 1991:33-8.

37 Roper WL. Current approaches to prevention of HIV infections. Public Health Rep 1991;106:111-5.

38 United States Conference of Mayors. CDC's prevention marketing initiative: a multi-level approach to HIV prevention. HIV Capsule Report 1994;2:1-8.

39 Smith WA, Helquist MJ, Jimerson AB, Coravano $\mathrm{K}$ Middlestadt SE, eds. A world against AIDS: communication for behavior change. Washington, DC:

40 Joinet B, Nkini WG. The "fleet of hope": offering options to achieve healthy behaviour. AIDS/STD Health Promotion Exchange 1996;2:3-6.

41 Darrow WW, Valdiserri RO. New directions for health promotion to prevent HIV infection and other STDs. In: Curtis $\mathrm{H}$, ed. Promoting sexual health. London: Chameleon Press, 1992:39-54.

42 O'Reilly KR, Higgins DL. AIDS Community Demonstration Projects for HIV prevention among hard-to-reach groups. Public Health Rep 1991;106:714-20.

43 Centers for Disease Control and Prevention. Communitylevel prevention of human immunodeficiency virus infection among high-risk populations: the AIDS Community Demonstration Projects. MMWR 1996;45(RR-6): 1-24.

44 Rietmeijer CA, Kane MS, Simons PZ, Corby NH, Wolitsk RJ, Higgins DI, et al. Increasing the use of bleach and condoms among injecting drug users in Denver: outcomes of a targeted, community-level HIV prevention program. targeted, community-

45 Kelly JA, St. Lawrence JS, Stevenson LY, Hauth AC, Kalichman SC, Diaz YE, et al. Community AIDS/HIV risk reduction: the effects of endorsements by popula people in three cities. Am F Public Health 1992;82:1483-9.

46 Kelly JA, St Lawrence JS, Diaz YE, Stevenson LY, Hauth AC, Brasfield TL, et al. HIV risk behavior reduction following intervention with key opinion leaders of popula-
tion: an experimental analysis. Am $\mathcal{f}$ Public Health 1991;81:168-71.

47 Asamoah-Adu A, Weir S, Pappoe M, Kanlisi N, Neequaye A, Lamptey P. Evaluation of a targeted AIDS prevention intervention to increase condom use among prostitutes in Ghana. AIDS 1994;8:239-46.

48 Bhave $G$, Lindan CP, Hudes ES, Desai $S$, Wagle U, Tripathi SP, et al. Impact of an intervention on HIV sexually transmitted diseases, and condom use among sex workers in Bombay, India. AIDS 1995;9(Suppl 1) S21-30.

49 Ngugi EN, Plummer FA, Simonsen JN, Cameron DW, Bosire M, Waiyaki P, et al. Prevention of transmission of human immunodeficiency virus in Africa: effectiveness of condom promotion and health education among prostitutes. Lancet 1988;2:887-90.

50 Visrutaratna S, Lindan CP, Sirhorachai A, Mandel JS. "Superstar" and "Model Brothel": developing and evaluating a condom promotion program for sex establishments in Chiang Mai, Thailand. AIDS 1995;9(Suppl 1):S69-75

51 Wilson D, Sibanda B, Mboyi L, Msimanga S, Dube G. A pilot study for an HIV intervention program among commercial sex workers in Bulawayo, Zimbabwe. Soc Sci Med 1990;31:609.

52 Helquist $M$, Sealy $\mathrm{G}$. One of our sons is missing: using theatre to confront sensitive issues. In: AIDS prevention through health promotion. Geneva: World Health Organisation,
1991:39-41.

53 Meyer L, Job-Spira, N, Bouyer J, Bouvet E, Spira A. Prevention of sexually transmitted diseases: a randomized community trial. $\mathcal{F}$ Epidemiol Community Health 1991;45: $152-8$

54 Reckless WC. Vice in Chicago. Chicago, Illinois: University of Chicago Press, 1933

55 Hill M, Mugge R. Syphilis prevalence as related to social factors in a Negro subcommunity. American fournal of Syphilis, Gonorrhea and Venereal Diseases 1954;38:583-92.

56 Darrow WW. Venereal infections in three ethnic groups in Sacramento. Am F Public Health 1976;66:446-50.

57 Darrow WW. A framework for preventing AIDS. Am 7 Public Health 1987;77:778-9.

58 Mooij AJ. Geslachtsziekten en Besmettingsangst, Een HistorischSociologische Studie 1850-1990. Amsterdam: Boom, 1993. 59 Rosenberg ML, Tolsma DD, Kolbe LJ, Kroger F, Cynamon $\mathrm{ML}$, Bowen GS. The role of behavioral sciences and health education in HIV prevention: experience at the US Centers for Disease Control. In: Sepulveda J, Fineberg H, Mann J, eds. AIDS prevention through education: a world view. New York: Oxford University Press, 1992:175-98.

60 Rosenstock IM, Strecher VJ, Becker MH. The health belief model and HIV risk behavior change. In: DiClemente RJ, Peterson JL, eds. Preventing AIDS: theories and methods of $\mathbb{D}$ behavioral interventions. New York. Plenum, 1994:5-24.

61 Fishbein M, Middlestadt SE, Hitchcock PJ. Using information to change sexually transmitted disease-related behaviors. In: DiClemente RJ, Peterson $\mathrm{JL}$, eds. Preventing AIDS: theories and methods of
York: Plenum, 1994:61-78.

62 Bandura A. Social cognition theory and exercise of control over HIV infection. In: DiClemente RJ, Peterson JL, eds. Preventing AIDS: theories and methods of behavioral interventions. New York: Plenum, 1994:25-59.

63 Prochaska JO, Redding CA, Harlow LL, Rossi JS, Velicar iN WF. The transtheoretical model of change and HIV pre- $\infty$ vention: a review. Health Educ $Q$ 1994;21:471-86.

64 Simon KJ, Das A. An application of the health belief model 윽 toward educational diagnosis for VD education. Health Educ $Q$ 1984;11:403-18.

65 Darrow WW. Approaches to the problem of venereal disease prevention. Prev Med 1976;5:165-75.

66 Oakley A, Fullerton D, Holland J. Behavioral interventions for HIV/AIDS prevention. AIDS 1995;9:479-86

67 Darrow WW. Evaluating behavioral interventions for HIV prevention. AIDS 1996;10:346-8.

68 Fisher JD, Fisher WA Changing AIDS-risk behavior. Psychol Bull 1992;111:455-74.

69 Kelly JA, St Lawrence JS. Behavioral group interventions to teach AIDS risk reduction skills: Project ARIES (AIDS Risk IntErvention Series). Jackson, Mississippi: University of Mississippi Medical Center, 1990

70 Kelly JA, St Lawrence JS, Betts R, Brasfield TL, Hood HV. A @ skills-training group intervention model to assist persons in $\overline{\bar{O}}$ reducing risk behavior for HIV infection. AIDS Educ Prev 1990;2:24-35.

71 Walter HJ, Vaughan $\mathrm{RD}$. AIDS risk reduction among a multiethnic sample of urban high school students. FAMA 1993;270:725-30

72 Rotheram-Borus MJ, Koopman C, Haignere C, Davies M. के Reducing HIV sexual risk behaviors among runaway adolescents. $\mathcal{F} A M A$ 1991;266:1237-41

73 Jemmott JB III, Jemmott LS, Fong GT. Reductions in HIV risk-associated sexual behaviors among black male adolescents: effects of an AIDS prevention intervention. Am 7 Public Health 1992;82:372-7.

74 Galavotti C, Cabral RJ, Lansky A, Grimley DM, Riley GE, 을 Prochaska JO. Validation of measures of condom and other contraceptive use among women at high risk for HIV infection and unintended pregnancy. Health Psychol 1995; 14:570-8

75 Choi K-H, Coates TJ. Prevention of HIV infection. AIDS SO 1994;8:1371-89.

76 Hart GJ. Hope for evidence-based HIV/AIDS prevention? AIDS 1996;10:337-8

77 Jones SG. Understanding community in the information age In: Jones SG, ed. Cybersociety, computer-mediated communication and

78 Shields R. Cultures of Internet: toward a social theory of cyber- $\mathrm{S}$ spaces and virtual realities. Thousand Oaks, CA: Sage, 1995.

79 Garrett L. The coming plague: newly emerging diseases in a world out of balance. New York: Farrar, Straus and Giroux, 1994.

80 Friede A, Blum HL, McDonald M. Public health informatics: how information-age technology can strengthen public health. Annu Rev Public Health 1995;16:239-52.

81 Maibach E, Holtgrave DR. Advances in public health communication. Annu Rev Public Health 1995;16:219-38.

82 Aral SO, Peterman TA. Defining behavioral methods to prevent sexually transmitted diseases through intervention research. Infect Dis Clin N Am 1993;7:861-73.

83 Hellinger FJ. The lifetime cost of treating a person with HIV. ЭAMA 1993;270:474-8

84 Curran JW, Morgan WM, Hardy AM, Jaffe HW, Darrow WW, Dowdle WR. The epidemiology of AIDS: current

85 Guinan ME, Farnham PG, Holtgrave DO. Estimating the value of preventing a human immunodeficiency virus infection. Am $\mathcal{F}$ Prev Med 1994;10:1-4.

86 Valdiserri RO, Aultman TV, Curran JW. Community planning: a national strategy to improve HIV prevention programs. f Community Health 1995;20:87-100. 